\title{
Erratum to: Genetic Screening of Pediatric Cavernous Malformations
}

Elisa Merello ${ }^{1}$ - Marco Pavanello ${ }^{1}$ - Alessandro Consales ${ }^{1} \cdot$ Samantha Mascelli $^{1}$. Alessandro Raso ${ }^{1} \cdot$ Andrea Accogli $^{1} \cdot$ Armando Cama $^{1} \cdot$ Valeria Capra $^{1}$. Patrizia De Marco $^{1,2}$

Published online: 3 November 2016

(C) Springer Science+Business Media New York 2016

Erratum to: J Mol Neurosci (2016) 60:232-238

DOI 10.1007/s12031-016-0806-8

The original version of this article unfortunately contained a mistake in the Author group section. Valeria Capra's surname and given name were inadvertently interchanged.

The authors apologize to readers for this error.

The online version of the original article can be found at http:// dx.doi.org/10.1007/s12031-016-0806-8.

\footnotetext{
Patrizia De Marco

patriziademarco@gaslini.org

1 Istituto Giannina Gaslini, Genoa, Italy

2 Dipartimento Testa-Collo e Neuroscienze, UOC Neurochirurgia, Istituto Giannina Gaslini, Genoa, Italy
} 